there is a very large proportion of grave injuries and of cases requiring surgical operation. At small country hospitals these conditions are all reversed. Is it rational to treat the respective death-rates as if they were aninflnevced by these circum. stances? But, perhaps, your readers will say, What proof have yon that they are so influenced ? The suggestion contained in your leading article, that a comparison of bospital registers would prove whether there was any, and if so what, difference in the nature of the cases admitted, would be a perfec!ly feasible one if these documents were more accurately compiled. But they are not made up with a view to medical accuracy, and the diseases are usually named in such vagne terms that little could be made out from them. A personal visit to each hospital will convince anyone acquainted with medicine how great is the difference between the proportion of diseases involving risk to life in a country and a metropolitan hospital, and it is on this personal examination of the matter, conducted at the great majority of the hospitals in Great Britain, that I mainly rest my assertion.* Again, the difference in death-race is far more in the medical cases than in the surgical, and it is to the merical cases that the above remarks far more apply. In some of the larger country towns, and especially in the practice of an actire surgeon, or a celebrated school of surgery, the average of surgical cases approaches in severity to that of a metropolitan hospital, and then so does the death-rate. Thus, to compare two hospitals, one in town, the other in the country-say, St. George's, London, and the Norwich Hospital. At the former, the deathrate for medical cases was, in $1862,11 \%$ per cent., and for surgical cases, 6.4 per cent. At the latter these rates were 5.02 and 5.14 respestively. Space does not allow me to give more than a few examples. The whole suliject, both of the value of hospital death-rates and of the respective healthiness of town and country, large and small hospitals, will be discnssed in the Report to which $I$ have referred, at as much length as the importance and the intricacy of the subject demand.

As to the death-rate, we have convineed ourselves that it is absolutely useless if employeil as a test of the sanitary condition of the hospital; that not only may a high dıath-rate consist with a good sanitary state, but that a very bad sanitary condition, one in which "hospital disease" is very rile, may consist with a low death-rate. As instances of the fallacy of arguing directly from the death-rate of an hispital to its sanitary condition, I may mention the following among many simlar facts :-The Southern Hospital at Liverpool was a few years since in an unsatisfactory sanitary condition, requiring improvements in drainage, and other requisites for hospital salubrity. These improvements were effected to the satisfaction of its managers. In the three years preceding the im. provements (and when the state of the hospital was relatively bad), the death-rate is given as 4.8 per cent.; while in the next three years after the improvements the death rate rose to to 6.06 per cent. The explanation is a very easy one. The funds were low, and the number of admissions had to be reduced in the latter period (2655 against $4>77$ in the former) : that is to say, the less severe cases were refused.

This shows how the death-rate may be raised while the sanitary condition of the hospital is not only not worse, but even palpably improved. Let me now give one instance of the very slight extent to which the attacks of hospital disease affect the annual death-rate. The figures given in the footnote below show that in $\mathbf{1 8 6 2}$ the number of deaths from pyæmia in the five large hospitals was less than one fiftieth of the whole number of deaths. It is not possible to give the precise number of deaths from erysipelas and phagedæna contracted in the hospital, since they are confused in the hospital returns with those from these diseases occurring before admis sion; bat it would be a most liberal statement, and one far beyond the true number, if we were to take them to be altogether equal to the deaths from pyænia, or the whole number of deaths from hospital diseases to be one twenty-fifth of the total deaths. Yet some persons appear to think that the presence or absence of hospital diseases is a sufficient ex. planation of a double or triple death-rate. If, in the year $1<62$, the deaths from hospital affections had been doubled, that fact, if known, would very probably have been held to indicate an unsatisfactory sanitary condition, and to call for minute examination; but it would have been hardly noticeable in the annual death rate. In the case supposed, the deaths would have risen from 1976 to 2046 , or in the proportion of $103 \cdot 7$ to 100 , a far less variation than occurs constantly from year to year from causes wholly accidental. This being so, Ineed not say

- Since writing the above, I have seen an excellent letter from Mr. Yeo, House-Surgeon to the Hospital at Winchester, proving this point most completely for that hospital. that I regard Dr. Farr's statistics as being utterly delusive; and if these are the whole foundation for the assertion that hospitals o harm instead of good, I should not hesitate to characterize hat assertion as reckless, and inconsistent with the facts.

As to country and town hospitals I may, perhaps, add a ingle word. We have visited all the principal establishments. in the United Kingdom and in Paris, and have tried to form an estimate of their practice and its results. So far from being prejudiced in favour of the London hospitals, I may say for myself that I started with a confident anticipation of finding: clear evidence that cases, especially surgical cases, did much better in the country; that hospital diseases were far more rare, and recovery more certain and speedy. I cannot say that we have found any such evidence. I believe further, that, so far from its being true that the smaller a hospital is the healthier it is, on the contrary, our large London bospitals are far more healthy than most of the smaller provincial hospitals, which latter, in fact, if they were filled with the acute medical cases and the large open wounds that abound in the former, would soon tell Dr. Farr a different tale. I think, however, that the comparisons I have made between various hospitals of different sizes, administered under the same plan, will show him that size can have little to do with the death-rates; while the fact that, under the same liberal regulations for the admission of disease, and with no allegation of hospital unhealthiness, the rate of death has been the same at Arbroath and at Glasgow, should make him hesitate before he attributes the differences to. town and country situations.

But the fact really is, that Dr. Farr is attempting to settle by statistics a question which mere fignres are not sufficient to solve. The figures can give only the bare facts; the explanation of the facts must be sought from accurate information as to the causes of death, and careful reasoning, if it be sought to connect those causes with bospital influence. I find no trace of this process in Dr. Farr's brief and (to me) somewhat obscureremalks.

One word in conclusion. An idea prevails in some quarters (where more accurate information might be expected) that physicians and surgeons, knowing the unhealthy state of the large hospitals, * are anxious to avoid inquiry into the matter. Nothing is more ludicrously erroneous. Oar only object is, and must necessarily be, for the sake of our own credit, if for no other reason, to save as many of our patients as possible. If any rational scheme could be devised by which this object would be accomplished, it would, you may be well assured, be warmly promoted by hospital physicians and surgeons. But everyone must deprecate hasty generalization from imperfect premisses, and strong language based upon weak facts. Our large hospitals appear to me to be the fittest places yet devised for the treatment of the sick poor, far more so than any other $\mathrm{d}$ wellings that have ever been put within their reach, and this belief has not been shaken by the figures produced by Dr. Farr. I am, Sir, your obedient servant,

Queen-street, May-fair, March, 1864. T. Holimes.

\section{"LITHOTRITY WITHOUT INJECTIONS."}

\section{To the Editor of The Laircer.}

SrR,-I am extremely gratified to learn that Mr. G. Pollock so thoroughly approves of and practises "lithotrity without preliminary injections." His paper is the first public testimony to the superiority of the plan which I recommended more than two years ago in my Lettsomian Lectures at the Medical Society of London, and published in Tue LaNCET of March 15th, 1862; and since that time, in my work on "Practical Lithotomy and Lithotrity"' (pp. 164-166), where he will find arguments for the method very similar to those adduced in the course of his remarks.

* Dr. Farr and others often speak of pyæmia as if it was a great cause of hospital mortality. I have the data for 1862 at hand, having collected them for that year, as being the last complete year when we were engaged upon the Report before named. Whether the deaths from pyæmia wera above or below Report before named. Whether the deaths from pyamia wera above or below
the average I have no idea. I find that the deaths returned from the five the average I have no idea. I find that the deaths returned from the five London hospitals, having more than 300 beds, which 1 presume to be intended by Dr. Farr's table-viz., St. Bartholomew's, Guy's, St. George's, the London, and the Middlesex Hospitals-were 1976 in that year. I have no account of the number of fatal cases of pyæmia at the Middlesex Hospital. At the other fonr hospitals they were 30 out of 1710 deaths; or if we consider the deaths at Middlesex to be in the same proportion, 35 cases out of the whole 1976 -that is to say, below 2 per cent. of fatal cases. It should not be forgotten that in some of these cases, psæmia had been develoned before admission, and was not a huspital disease at all. In the records of death in country hospitals pyamia is, perkaps, a little less common, but not so much so as the milder class of their approach of the surgical injuries to the average severity of those in London. 
But while Mr. Pollock supports so warmly the practice, he favours the writer with a criticism or two which require reply. I must ask your indulgence in occupying space for matters which appear to me very trifling, but Mr. Pollock has made them so prominent that no other alternative exists.

It is stated first that the practice I advocate is not new.

In any sense of the word " new" employed by the inspired writer whom Mr. Pollock has thought fit to invoke in this very small matter I have never spoken of my practice. I have only stated that it was not " usual," and on this ground I desired to call attention to it. Will Mr. Pollock point out to me a single recommendation of the rule to perform "lithotrity without injections" in any one of the numerous works on the subject which describe the operation? If not, I claim to have been the first to publish the superiority of this over the "usual" mode.

Next, Mr. Pollock objects to my use of the word "sitting ;" and believes "that on consideration I must see that this term is misapplied, and is apt to mislead."

I have long used (in print) the word "gitting" in the sense referred to, and not without some consideration, for the following reasons :-

1st. " Sitting" is recognised as the best English equivalent for the word "séance" employed by French operators and writers to denote a single application of crushing and other instruments on any given day to a stone in the bladder. The literature and practice of France in relation to this subject are much more extended than our own, and I could not assume the right to propose another term. I do not learn that Mr. Pollock has thought right to do so.

2ndly. The application of the word is phil logically correct. I gratefully acknowledge any suggestion, even $i$ is the form of admonition, from Mr. Pollock, tending to promote accuracy in the employment of language; and I fully coincide in his most just appreciation of its importance. He will find, however, in our best dictionaries overwhelming proof that the word "sitting" is by no means limited in its meaning to denote any one posture; and that it may still be used correctly to describe a "séance" of lithotrity, although, as it is gravely remarked, - the patient is on his back, and the operator stands by his side!" I adduce the two best anthorities.

JoHNSON : "Sit (3), to be in a state of rest; (4), to be in any locaì condition."

RICHARDSON : "Sit, to be or cause to be in any place, position, or posture; in any state, situation, or condition : ...... applies to a posture of rest as distinguished from standing or kneeling."

Thus much in self -defence.

There is one remark, now, which I desire to make respecting the operation itself. Mr. Pollock speaks of lithotrity as "of all operations in surgery one of the most simple," \&c. Whatever "simple" may mean in that context, I wish to express my strong conviction that there is no operation which requires more practice and experience, more manual tact and delicacy, more care and prudence in its performance, and a more complete armamentarium than lithotrity, if it is to be done "tuto, cito, et jucunde."

I am, Sir, your obedient servant,

Wimpole-street, March, 1864. HENRY THOMPsON, F.R.C.S.E.

\section{To the Editor of THE LANCET.}

SrR,-The question raised under the above heading by Messrs. Thompson and Pollock may be interesting in eliciting the opinion of London surgeons. In performing the operation of lithotrity, I never think of witbdrawing the urine from the bladder, trusting that the viscus is sufficiently dilated by the natural secretion. Nor do I inject warm water, unless the walls of the bladder are so much contracted is to prevent the proper manipulation of the lithotrite. But I am not aware that this practice can lay any claim to novelty.

Lithotrity, however, is an operation by no means free from danger. In selected cases-where, for example, in a gouty subject, a small lithic-acid calculus drops, from year to year, into the bladder of an aged man-its employment is invaluable. But in general cases it fails in its end, and when often repeated it finally leads to general disturbance of the constitution, when it ends fatally. - I am, Sir, yours \&c.,

Holmes Coote, F.R.C.S. Queen Anne-street, Cavendish-square, March, 1864.

New Hospital for Chorlton.on-Medlock.-A new hospital is about to be erected at Withington, Chorlton-onMedlock.

\section{SURGERY AT THE SEAT OF WAR IN SCHLESWIG.}

(Communicated by Lovis Stromerer Lirrte, AssistantSurgeon to the London Hospital.

Amonast the cases in the different hospitals of Schleswig were many of that singular injury to the chest in which the ball, striking the ribs, traverses the semi-circumference of the chest subcutaneously. Of these cases I saw nearly a dozen. I was told by Anstrian surgeons, who had made the campaign in Italy in 1859 , that no such cases were met with there. If this be so, and there is no reason to doubt the accuracy of observa. tion of these gentlemen, the interesting question arises, whether there was anything in the nature of the missiles or weapons used to account for it. It cannot be that here the bullet was deficient in momentum, and, consequently, in penetrating power, and therefore acted as a spent ball, for at the fight of Oversee, from which the wounded in question were brought, the men were engaged at close quarters. It is possible that this difference in the results observed in the Italian and in the present campaign may be due to the variation in the size of the bullet used by the respective combatants. The rifle bullet of the Danes is of large diameter, and weighs nearly two ounces, that used by the French and Austrians being about half the size. The question is the more perplexing since amongst these wounded were one or more Danes.

Tetanus figured rather largoly in Schleswig, eight soldiers with gunshot wounds having already succumbed to it, and none having recovered. Most of these were only slightly wounded. In one on whom I made a post-mortem examination, the ball had merely passed through the integuments of the posterior fold of the axilla, slightly grazing the muscle. The wound had not healed, and did not exhibit a healthy supporating surface. When I left Schleswig there were three others affected with tetanus with little hopes of recovery. Various modes of treatment were tried, and, locally, hot and cold applications to the spine. There was also a noteworthy paucity of typhus and pyæmia, * and no case of hospital gangrene had hitherto been seen.

I left Schleswig farourably impressed on the whole with the hygienic arrangements and with the natural advantages of the locality as a place for the formation of military hospitals and for the treatment of the numerous wounded. I had there an opportunity of observing the unbounded liberality of the German public, in having forwarded from all parts of Austria, Prussia, and the rest of the Confederation, ample supplies of every comfort and every luxury that conld alleviate the sufferings of the wounded, whether Germans or Danes.

At Flensburg the number of wounded did not exceed 200, the majority being Danes, from the engagements at Missunde, Oversee, and Diippel. I found one hospital here under the direction of Dr. Heine, of Canstatt, known in London from his visits to our hospitals. Here there were many interesting cases, amongst others a slight gunshot wound of the chest, the track of the ball having healed by the first intention-without suppu. ration, it was said. It must be extremely rare, and I can scarcely believe it possible for a gunshot wound to heal without the formation of pus. One of the most interesting consequences of bullet wounds which I noted here, was paralysis in almost all its forms-for example, of the facial nerve, from a ball which had entered behind the left mastoid process, emerging over the left ala nasi, fracturing both the temporal and superior maxillary bones. This patient was doing well. Another had been struck by a piece of a shell at the junction of the occipital and parietal bones, and had a depressed fracture at that spot: his only cerebral symptom was very considerable imperfection of the sight of both eyes. Another had received when stooping a bullet slightly below the spine of the scapula, which had appa. rently passed downwards, but had not emerged. This patient had complete paralysis both of motion and sensation of all parts below the last rib.

In this small town (Hadersleben) large hospitals are being established by both Austrians and Prussians in anticipation of the expected advance into Jutland, from which it is distant about fifteen miles. Like all the small towns in this country, Hadersleben possesses several buildings of considerable size

* I have since learned that pyæmia has become more prevalent, from col lecting the worse class of injuries in the same wards. 